\title{
GATA4 zinc finger mutations as a molecular rationale for septation defects of the human heart
}

\section{S M Reamon-Buettner, J Borlak}

J Med Genet 2005;42:e32 (http://www.jmedgenet.com/cgi/content/full/42/5/e32). doi: 10.1136/jmg.2004.025395

G ATA4 is localised on human chromosome 8p23.1-p22 and codes for a zinc finger transcription factor. Mice lacking Gata4 suffer from defective ventral morphogenesis and heart tube formation. ${ }^{12}$ This factor therefore targets various genes important for heart development and basic cardiac function. Recently, three GATA4 mutations have been detected in families with congenital heart disease. ${ }^{34} \mathrm{~A}$ mutation affecting a residue next to the C-terminal zinc finger has been identified in family members with atrial septal defects, and resulted in the disruption of a physical interaction between Gata4 and TBX5. ${ }^{3}$ There is growing evidence that the two zinc fingers of Gata4 display distinct functions so as to facilitate protein-DNA and protein-protein interactions.

To further our understanding of the specific role of GATA4 in human congenital heart disease, we searched for mutations in the sequences coding for the zinc fingers in diseased heart tissues of 68 patients with complex heart malformations, encompassing atrial (ASD), ventricular (VSD), and atrioventricular septal defects (AVSD). These patients mostly died in early infancy as a result of the severity of the cardiac abnormalities. We isolated genomic DNA from the formalin fixed malformed hearts, amplified exons 3 and 4 from DNA fragments of about $2 \mathrm{~kb}$, and carried out double strand direct sequencing. Mutations were confirmed by polymerase chain reaction restriction fragment length polymorphism (PCRRFLP) or cloning and subsequent sequencing to separate alleles (fig $\mathrm{IA}-\mathrm{F}$ ).

We identified 23 mutations, of which several are located in the zinc fingers and basic regions of GATA4 (table 1). Except for three, the genotypes observed in our collection of 68 hearts were mostly heterozygous, as seen on sequence electropherograms. Some patients had two to four mutations, including four with mutations in both zinc fingers of GATA4. Cloning of a fragment from a patient heterozygous for two zinc $\mathrm{N}$-finger mutations showed location on different alleles. Additional cloning of a fragment heterozygous for three nonsynonymous mutations $($ c.631T $\rightarrow$ C, c.687G $\rightarrow$ T, c.731A $\rightarrow \mathrm{G}$ ) gave three haplotypes after sequencing of four clones-that is, one clone with all three reference alleles (c.631T, c.687G, c.731A), two clones with one mutant allele (c.631T, c.687T, c.731A), and one clone with two mutant alleles (c.631C, c. $687 \mathrm{G}$, c. $731 \mathrm{G})$. These mutations were absent in DNA isolated from 10 normal formalin fixed hearts, five frozen normal hearts, and 50 blood samples from unrelated healthy individuals used as controls.

\section{COMMENT}

Although our heart collection is basically homogeneous with respect to septation defects, we found 21 hearts that did not carry mutations in the zinc fingers and adjacent amino acids. This suggests that additional molecular changes result in a similar disease phenotype. It is of importance that mutations were absent in unaffected tissues of the same heart (table 1), and this agrees well with our findings on NKX2-5. ${ }^{5}$ We

\section{Key points}

- GATA4 is a zinc finger transcription factor and master regulator of heart development.

- A zinc finger mutation was identified which affects a zinc coordinating cysteine in the $\mathrm{C}$-terminal finger and which is strongly associated with ventricular septal defects.

- GATA4 zinc finger mutations were shown to affect DNA binding, contacts on zinc ion, and protein secondary structure.

- Impaired GATA4 interaction with the third helix of the homeodomain of NKX2-5 results in septation defects of the human heart.

therefore show that GATA4 zinc finger mutations also occur somatically, most probably from cell division errors during early embryogenesis. Notably, among the mutations is c.874T $\rightarrow$ C (Cys292Arg), which is located in the C-terminal zinc finger, affects one of the four zinc coordinating cysteines, and is predicted to disrupt the secondary structure of the Cfinger (fig lG). This mutation was detected in 19 of 29 VSDs, six of 16 ASDs, and six of 23 AVSDs. Many affected VSDs had a subaortic VSD with overriding aorta together with other cardiac anomalies. For instance, patient D03VSD had a subaortic/subpulmonic VSD with overriding aorta, a patent foramen ovale, a patent ductus arteriosus, and a double outlet left ventricle.

Gata4 regulates expression of genes through its zinc fingers. The N-terminal zinc finger interacts with Fog2, and replacement of an amino acid (mouse Val217Gly) in the Nfinger impairs physical interactions. ${ }^{7}$ Mutant mice died at E12.5 and showed semilunar cardiac valve defects and a double outlet right ventricle. We found six mutations in the $\mathrm{N}$-finger of GATA4, including a homozygous deletion (677delC) that would lead to a frameshift mutation affecting critical residues. The patient with this mutation had subaortic VSD, septum primum defect ( $15 \mathrm{~mm}$ ), patent foramen ovale, patent ductus arteriosus, and a common atrioventricular canal. Disruption of GATA4-FOG2 interaction most probably contributed to the cardiac anomalies of this patient. Further, four of the mutations that we found in the N-finger are highly conserved amino acids and may also affect DNA binding or protein-protein interactions of GATA4.

The C-terminal zinc finger is required for the many interactions of Gata4 including Nf-At $3^{8}$ and $\mathrm{Nkx} 2-5^{9-12}$ resulting in transcriptional synergy of regulated genes. Gata4-Nkx2-5 interaction involves the third helix (homeodomain) of Nkx2-5 and the C-finger of Gata4. Mutagenesis experiments involving the zinc coordinating

Abbreviations: ASD, atrial septal defect; AVSD, atrioventricular septal defect; VSD, ventricular septal defect 
A

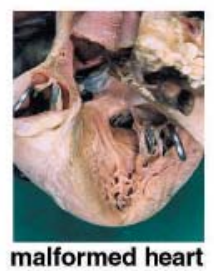

malformed heart
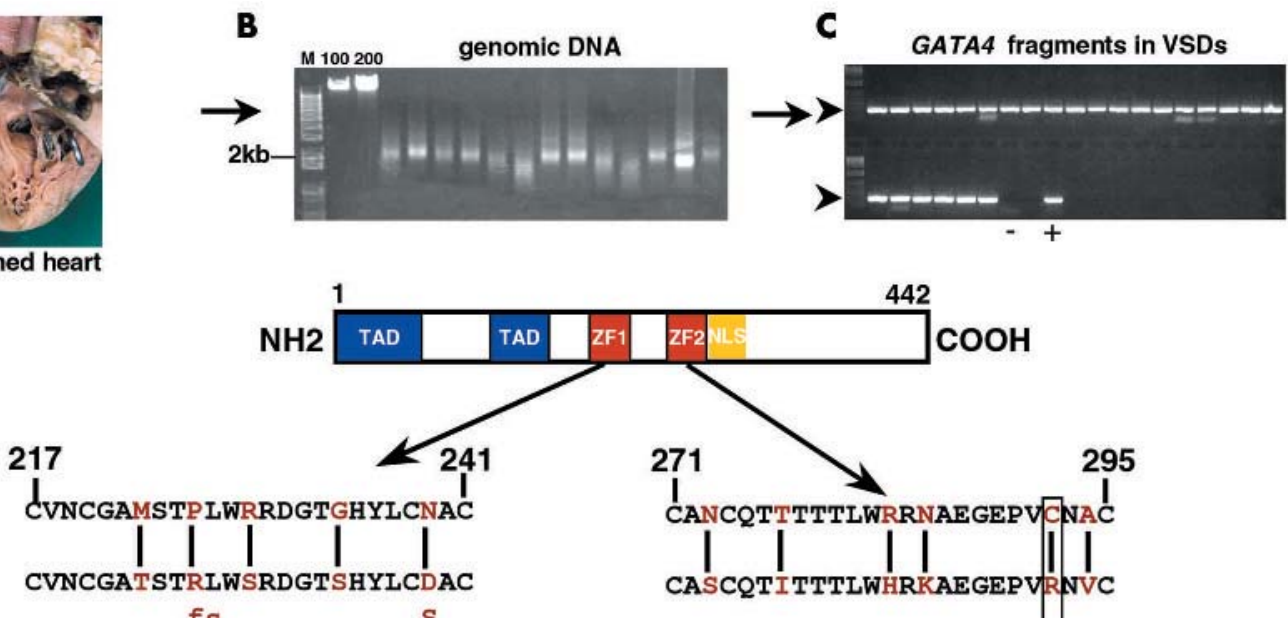

fs

$\mathrm{S}$

E
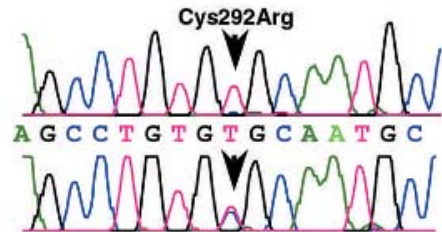

A G C C T G T G Y G C A A T G C

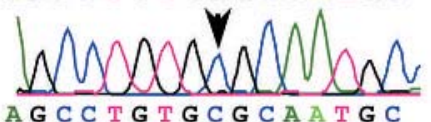

$\mathbf{F}$

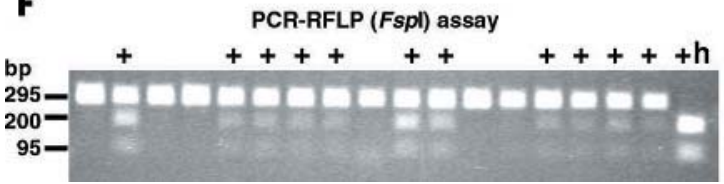

G

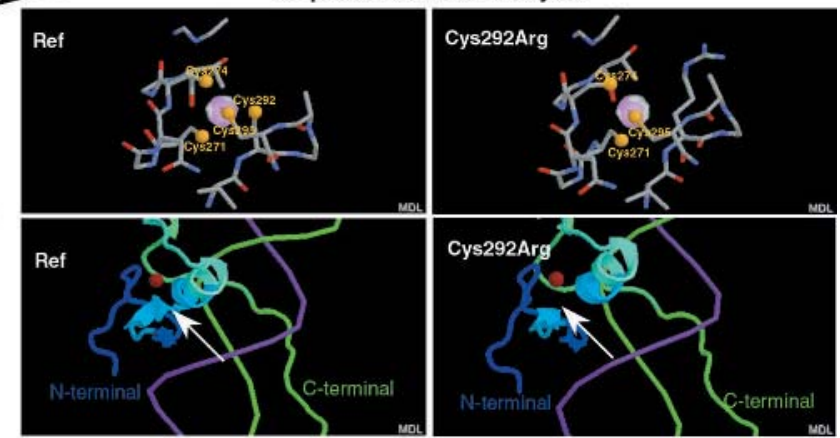

3D protein structure analysis

Figure 1 Analysis of GATA4 mutations in malformed human hearts. (A) DNA was isolated from the affected tissues of 68 formalin fixed hearts with complex cardiac malformations. (B) Genomic DNA was about $2 \mathrm{~kb}$ and $50 \mathrm{ng}$ was used for polymerase chain reaction (PCR). (C) Exons 3 and 4 of GATA4 were amplified to analyse mutations affecting the two zinc fingers; arrows show exon 4 fragments; - / depicts negative and positive controls, respectively. (D) The domains of GATA4 and location of identified mutations in the two zinc fingers, especially Cys292Arg which affects one of the four zinc coordinating cysteines in the $\mathrm{C}$-terminal finger and prevalent in hearts with subaortic ventricular septal defects with overriding aorta (E) Sequence analysis of Cys292Arg, showing homozygous (for T or C) and heterozygous genotypes (Y). (F) PCR-RFLP (restriction fragment length polymorphism) assay for Cys292Arg, which creates a site for Fspl; +h denotes a homozygous genotype for the mutation. (G) The effect of Cys292Arg on protein structure was determined using the C-terminal domain of chicken Gatal bound to DNA as a model (PDB id: 2gat), Swiss-PdbViewer (http:// expasy.org/spdbv/) and Protein Explorer (http://proteinexplorer.org). Left panels are the reference structures; the right panels are with cysteine in position 292 mutated to arginine. Upper panels show important residues near the ligand zinc, particularly sulphur atoms (yellow) of the four coordinating cysteines. Lower panels show the ribbon structure and Cys292Arg disrupts the secondary structure (arrow).

cysteines abolished DNA binding, binding ability to Nkx2-5 and synergy. ${ }^{90}$ Our mutation Cys292Arg will certainly have the same outcome to result in loss of NKX2-5-GATA4 protein-protein interaction, and this was highly associated with septation defects in our patient cohort. This mutation was prevalent in VSDs as compared to ASDs and AVSDs.

We detected further five C-finger mutations in AVSDs, of which three were also highly conserved residues. Using the C-terminal domain of chicken Gatal bound to DNA as a template (see PDB id: 2gat), Swiss-PdbViewer (http:// expasy. org/spdbv/) and Protein Explorer (http://proteinexplorer.org), we located homologous residues and predicted the consequence of mutations on DNA binding, contacts on zinc, and protein secondary structure. Two of the five mutations would affect 19Arg and 30Ala, which are in close contact with the DNA. Indeed, mutations Arg283His and Ala294Val would weaken but not abolish DNA contact, although it has been shown, that mutants on the C-finger with intact DNA binding ability may still abolish Gata4-Nkx2-5 interaction and synergy. ${ }^{10}$ Further, mutation Ala294Val will disrupt the secondary structure similar to Cys292Arg (fig.1G).
Next to Nkx2-5, the Gata4 C-finger also interacts with the basic helix-loop-helix (bHLH) domain of dHand to activate synergistically the expression of heart specific genes such as atrial natriuretic factor (ANF), the brain type natriuretic peptide (BNP) and the $\alpha$-myosin heavy chain $(\alpha \mathrm{MHC}) .{ }^{13}$ The residues WRR (mouse, 281-283 WRR) are critical for the interactions with dHand, which in turn are crucial for Gata4 interaction with a coactivator, p300. ${ }^{14}$ We found one AVSD patient with the mutation Arg283His, which affects one of these critical residues. This patient had subaortic VSD with overriding aorta, septum primum defect, patent foramen ovale, and a common atrioventricular canal. The Gata4 Cfinger likewise interacts with the DNA binding domains of Mef2 proteins to activate ANF, BNP, $\alpha$ MHC, and $\alpha$ cardiac actin ( $\alpha \mathrm{CA}$ ) synergistically. ${ }^{15} \mathrm{~A}$ point mutation in one of the zinc coordinating cysteines (mouse, Cys273Gly) that had abolished Gata4 DNA binding and Gata4-Nkx2-5 physical interaction ${ }^{9}$ likewise destroyed Gata4-Mef2 synergy. Moreover, it has been shown that the C-finger and adjacent basic domain of Gata4 are required for interaction with Smad proteins in the activation of Nkx2-5. ${ }^{16}$ A double mutant (mouse 
Table 1 Summary of GATA4 mutations

\begin{tabular}{|c|c|c|c|c|c|c|c|}
\hline $\begin{array}{l}\text { Nucleotide } \\
\text { change }\end{array}$ & $\begin{array}{l}\text { Amino acid } \\
\text { change }\end{array}$ & Location & $\begin{array}{l}\text { Positive } \\
\text { hearts } \\
\text { (VSD) }\end{array}$ & $\begin{array}{l}\text { Positive } \\
\text { hearts } \\
\text { (ASD) }\end{array}$ & $\begin{array}{l}\text { Positive } \\
\text { hearts } \\
\text { (AVSD) }\end{array}$ & $\begin{array}{l}\text { PCR-RFLP } \\
\text { assay }\end{array}$ & $\begin{array}{l}\text { Matched healthy } \\
\text { heart tissue }\end{array}$ \\
\hline c. $622 \mathrm{~T} \rightarrow \mathrm{C}$ & Phe208 Leu & exon 3 & 1 & & & & E22VSD, absent \\
\hline c. $631 \mathrm{~T} \rightarrow \mathrm{C}$ & Phe211Leu & exon 3 & 1 & & 1 & & \\
\hline c. $640 \mathrm{G} \rightarrow \mathrm{A}$ & Gly214Ser & exon 3 & 1 & & & & \\
\hline c. $668 \mathrm{~T} \rightarrow \mathrm{C}$ & Met223Thr & exon 3,1 st zinc finger & 1 & & & Tail & E27VSD, absent \\
\hline c.677delC & Pro226fs & exon 3,1 st zinc finger & & & $1^{*}$ & & F08AVSD, absent \\
\hline c. $687 \mathrm{G} \rightarrow \mathrm{T}$ & Arg229Ser & exon 3,1 st zinc finger & 1 & 1 & 1 & Taql & E27VSD, absent \\
\hline c. $700 \mathrm{G} \rightarrow \mathrm{A}$ & Gly234Ser & exon 3,1 st zinc finger & & & 1 & Hinfl & C70/2AVSD, absent \\
\hline c. $715 \mathrm{~A} \rightarrow \mathrm{G}$ & Asn239Asp & exon 3,1 st zinc finger & 1 & & & & \\
\hline c. $716 \mathrm{~A} \rightarrow \mathrm{G}$ & Asn239Ser & exon 3,1 st zinc finger & 1 & & & & \\
\hline c.731A $\rightarrow \mathrm{G}$ & Tyr244Cys & exon 3 , basic region & 1 & & 1 & & \\
\hline c.743A $\rightarrow \mathrm{G}$ & Asn248Ser & exon 3 , basic region & & 1 & 1 & $B s r B I$ & F02AVSD, absent \\
\hline c.755G $\rightarrow C$ & Arg252Pro & exon 3 , basic region & & & 1 & & C70/2AVSD, absent \\
\hline c. $764 \mathrm{~T} \rightarrow \mathrm{C}$ & Ile255Thr & exon 3 , basic region & & 1 & & & \\
\hline c. $779 \mathrm{G} \rightarrow \mathrm{A}$ & Arg260Gln & exon 3 , basic region & 1 & & & MspA1I & \\
\hline c.782T $\rightarrow C$ & Leu261Pro & exon 3 , basic region & 1 & 1 & & & \\
\hline c. $796 \mathrm{C} \rightarrow \mathrm{T}$ & Arg266Ter & exon 4 & & & $1^{*}$ & MspA1I & F12AVSD, absent \\
\hline c. $818 \mathrm{~A} \rightarrow \mathrm{G}$ & Asn273Ser & exon 4,2 nd zinc finger & & & 1 & Alul & F28AVSD, absent \\
\hline c. $830 \mathrm{C} \rightarrow \mathrm{T}$ & Thr277lle & exon 4,2 nd zinc finger & & & 1 & Hphl & \\
\hline c. $848 \mathrm{G} \rightarrow \mathrm{A}$ & Arg283His & exon 4,2 nd zinc finger & & & 1 & Hhal & E43AVSD, absent \\
\hline c. $855 \mathrm{~T} \rightarrow \mathrm{G}$ & Asn285Lys & exon 4,2 nd zinc finger & & & 1 & BseMl & \\
\hline c. $874 \mathrm{~T} \rightarrow \mathrm{C}$ & Cys292Árg & exon 4, 2nd zinc finger & $19^{*}$ & 6 & 6 & Fspl & in 20 matches, absent \\
\hline $\mathrm{c.} .881 \mathrm{C} \rightarrow \mathrm{T}$ & Ala294Val & exon 4,2 nd zinc finger & & 1 & & & \\
\hline c. $905 \mathrm{~A} \rightarrow \mathrm{G}$ & His302Arg & exon 4 , basic region, $\mathrm{nls}$ & & & 1 & Sadl & \\
\hline
\end{tabular}

*Homozygous genotypes observed.

+1 in nucleotide numbering is A of start codon ATG.

nls, nuclear localisation signal.

Cys270Gly/Cys273Gly) in the C-finger of Gata4 abolished binding and disrupted interaction with Smad factors.

There is much evidence that Gata4 participates in combinatorial interactions in regulating gene expression of cardiac genes. Crucial for these interactions are the zinc fingers, especially the C-terminal zinc finger. Recently, zinc deficiency in rats was shown to result in impaired Gata4 expression and complex cardiac anomalies ${ }^{17}$ Here we report zinc finger mutations, one of which disrupts zinc coordination and was highly associated with ventricular septal heart defects. Further, we identified in the same cohort of mutations in the binding domains of NKX2-5 ${ }^{5}$ and TBX5. ${ }^{18}$ It will therefore be interesting to determine whether these mutations will disrupt GATA4-NKX2-5 or GATA4-TBX5 combinatorial interactions to contribute to complex cardiac malformations.

\section{ACKNOWLEDGEMENTS}

We wish to acknowledge the technical support of Si-Hyen Cho, Annika Roskowetz, and Andreas Hiemisch as well as the financial support of the Lower Saxony Ministry of Science and Culture to JB.

\section{Authors' affiliations}

S M Reamon-Buettner, J Borlak, Drug Research and Medical Biotechnology, Fraunhofer Institute of Toxicology and Experimental Medicine, Hanover, Germany

Competing interests: none declared

Correspondence to: Professor J Borlak, Drug Research and Medical Biotechnology, Fraunhofer Institute of Toxicology and Experimental Medicine, Nikolai-Fuchs-Strasse 1, D-30625 Hanover, Germany; borlak@item.fraunhofer.de

\section{REFERENCES}

1 Kuo CT, Morrisey EE, Anandappa R, Sigrist K, Lu MM, Parmacek MS, Soudais C, Leiden JM. GATA4 transcription factor is required for ventral morphogenesis and heart tube formation. Genes Dev 1997; 11:1048-60. 2 Molkentin JD, Lin Q, Duncan SA, Olson EN. Requirement of the transcription factor GATA4 for heart tube formation and ventral morphogenesis. Genes Dev 1997;11:1061-72.
3 Garg V, Kathiriya IS, Barnes R, Schluterman MK, King IN, Butler CA Rothrock CR, Eapen RS, Hirayama-Yamada K, Joo K, Matsuoka R, Cohen JC, Srivastava D. GATA4 mutations cause human congenital heart defects and reveal an interaction with TBX5. Nature 2003:424:443-7.

4 Okubo A, Miyoshi O, Baba K, Takagi M, Tsukamoto K, Kinoshita A, Yoshiura K, Kishino T, Ohta T, Niikawa N, Matsumoto N. A novel GATA4 mutation completely segregated with atrial septal defect in a large Japanese family. J Med Genet 2004;41:e97.

5 Reamon-Buettner SM, Hecker H, Spanel-Borowski K, Craatz S, Kuenzel E, Borlak J. Novel NKX2-5 mutations in diseased heart tissues of patients with cardiac malformations. Am J Pathol 2004; 164:2117-25.

6 Reamon-Buettner SM, Borlak J. Somatic NKX2-5 mutations as a novel mechanism of disease in complex congenital heart disease. J Med Genet 2004:41:684-90.

7 Crispino JD, Lodish MB, Thurberg BL, Litovsky SH, Collins T, Molkentin JD, Orkin SH. Proper coronary vascular development and heart morphogenesis depend on interaction of GATA-4 with FOG cofactors. Genes Dev 2001:15:839-44.

8 Molkentin JD, Lu JR, Antos CL, Markham B, Richardson J, Robbins J, Grant SR, Olson EN. A calcineurin-dependent transcriptional pathway for cardiac hypertrophy. Cell 1998;93:215-28.

9 Durocher D, Charron F, Warren R, Schwartz RJ, Nemer M. The cardiac transcription factors $\mathrm{Nkx2-5}$ and GATA-4 are mutual cofactors. EMBO J 1997:16:5687-96.

10 Lee Y, Shioi T, Kasahara H, Jobe SM, Wiese RJ, Markham BE, Izumo S. The cardiac tissue-restricted homeobox protein $\mathrm{Csx} / \mathrm{Nkx} 2.5$ physically associates with the zinc finger protein GATA4 and cooperatively activates atrial natriuretic factor gene expression. Mol Cell Biol 1998;18:3120-29.

11 Sepulveda JL, Belaguli N, Nigam V, Chen CY, Nemer M, Schwartz RJ. GATA4 and Nkx-2.5 coactivate Nkx-2 DNA binding targets: role for regulating early cardiac gene expression. Mol Cell Biol 1998;18:3405-15.

12 Kasahara H, Usheva A, Ueyama T, Aoki H, Horikoshi N, Izumo S Characterization of homo- and heterodimerization of cardiac $\mathrm{Csx} / \mathrm{Nkx} 2.5$ homeoprotein. J Biol Chem 2001;276:4570-80.

13 Dai YS, Cserjesi P, Markham BE, Molkentin JD. The transcription factors GATA4 and dHAND physically interact to synergistically activate cardiac gene expression through a p300-dependent mechanism. J Biol Chem 2002;277:24390-8.

14 Dai YS, Markham BE. p300 Functions as a coactivator of transcription factor GATA-4. J Biol Chem 2001;276:37178-85.

15 Morin S, Charron F, Robitaille L, Nemer M. GATA-dependent recruitment of MEF2 proteins to target promoters. EMBO J 2000;19:2046-55.

16 Brown CO, Chi X, Garcia-Gras E, Shirai M, Feng XH, Schwartz RJ. The cardiac determination factor, Nkx2-5, is activated by mutual cofactors GATA4 and Smad1/4 via a novel upstream enhancer. J Biol Chem 2004:279:10659-69.

17 Duffy JY, Overmann GJ, Keen CL, Clegg MS, Daston GP. Cardiac abnormalities induced by zinc deficiency are associated with alterations in the expression of genes regulated by the zinc-finger transcription factor GATA-4. Birth Defects Res Part B Dev Reprod Toxicol 2004;71:102-9.

18 Reamon-Buettner SM, Borlak J. TBX5 mutations in non-Holt-Oram syndrome (HOS) malformed hearts. Hum Mutat 2004;24:104. 